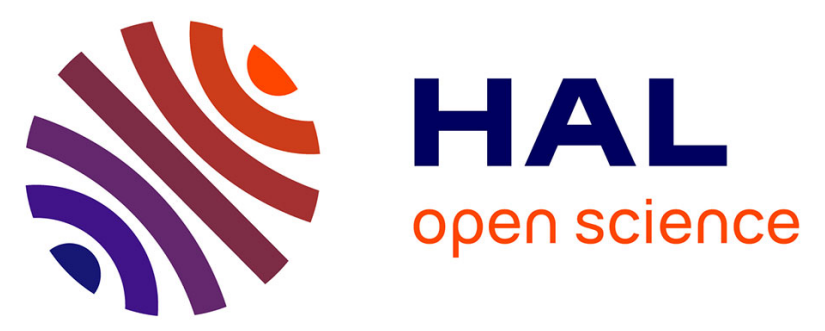

\title{
Recombinant production of eight human cytosolic aminotransferases and assessment of their potential involvement in glyoxylate metabolism
}

Stefano Donini, Manuela Ferrari, Chiara Fedeli, Marco Faini, Ilaria Lamberto, Ada Serena Marletta, Lara Mellini, Michela Panini, Riccardo Percudani, Loredano Pollegioni, et al.

\section{To cite this version:}

Stefano Donini, Manuela Ferrari, Chiara Fedeli, Marco Faini, Ilaria Lamberto, et al.. Recombinant production of eight human cytosolic aminotransferases and assessment of their potential involvement in glyoxylate metabolism. Biochemical Journal, 2009, 422 (2), pp.265-272. 10.1042/BJ20090748 . hal-00479195

\section{HAL Id: hal-00479195 https://hal.science/hal-00479195}

Submitted on 30 Apr 2010

HAL is a multi-disciplinary open access archive for the deposit and dissemination of scientific research documents, whether they are published or not. The documents may come from teaching and research institutions in France or abroad, or from public or private research centers.
L'archive ouverte pluridisciplinaire HAL, est destinée au dépôt et à la diffusion de documents scientifiques de niveau recherche, publiés ou non, émanant des établissements d'enseignement et de recherche français ou étrangers, des laboratoires publics ou privés. 


\section{Recombinant production of eight human cytosolic aminotransferases and assessment of their potential involvement in glyoxylate metabolism.}

Stefano Donini ${ }^{*}$, Manuela Ferrari ${ }^{*}$, Chiara Fedeli ${ }^{\star}$, Marco Faini ${ }^{*}$, Ilaria Lamberto ${ }^{\star}$, Ada Serena Marletta*, Lara Mellini ${ }^{*}$, Michela Panini, Riccardo Percudani ${ }^{*}$, Loredano Pollegioni $^{\dagger}$, Laura Caldinelli ${ }^{\dagger}$, Stefania Petrucco ${ }^{* 1}$ and Alessio Peracchi ${ }^{* 2}$

\footnotetext{
* Department of Biochemistry and Molecular Biology, University of Parma, 43100 Parma, Italy

† The Protein Factory - Department of Biotechnology and Molecular Sciences, University of Insubria, 21100 Varese, Italy.

${ }^{\ddagger}$ Current address: European Molecular Biology Laboratory, Meyerhofstrasse 1, 69117 Heidelberg, Germany
}

${ }^{1}$ Professor Stefania Petrucco prematurely passed away on February 23, 2009. This paper is dedicated to her memory.

${ }^{2}$ Corresponding author. Phone: (39) 0521905137 Fax: (39) 0521905151. Email: peracchi@unipr.it

Running title: Cytosolic aminotransferases involved in glyoxylate metabolism

Keywords: pyridoxal-phosphate; glyoxylate; transaminase; hyperoxaluria

Abbreviations: PH1, Primary hyperoxaluria type 1; PLP, pyridoxal 5'-phosphate; GO, glycine oxidase. AGXT alanine-glyoxylate aminotransferase isoform 1 (normally peroxisomal); AGXT2 alanine-glyoxylate aminotransferase isoform 2 (mitochondrial). GRHPR, glyoxylate reductase/hydroxypyruvate reductase. LDH, lactate dehydrogenase. Other enzyme acronyms are given in the legend of Table 1. Italicized acronyms refer to the genes; non-italicized acronyms refer to the corresponding proteins. 


\section{SYNOPSIS}

Primary hyperoxaluria type $1(\mathrm{PH} 1)$ is a severe inborn disorder of glyoxylate metabolism, caused by a functional deficiency of the peroxisomal enzyme alanine:glyoxylate aminotransferase (AGXT), which converts glyoxylate to glycine using L-alanine as the amino-group donor. Even though pre-genomic studies indicate that other human transaminases can convert glyoxylate to glycine, in $\mathrm{PH} 1$ patients these enzymes are apparently unable to compensate for the lack of AGXT - perhaps due to their limited levels of expression, or to their localization in an inappropriate cell compartment, or to the scarcity of the required amino-group donor. Herein, we describe the cloning of eight human cytosolic aminotransferases, their recombinant expression as His6-tagged proteins and a comparative study on their ability to transaminate glyoxylate, using any standard amino acid as an amino-group donor. To selectively quantitate the glycine formed, we have developed and validated an assay based on bacterial glycine oxidase (GO); this assay allows the detection of enzymes that produce glycine by transamination, in the presence of mixtures of potential amino-group donors and without separation of the product from the substrates. We show that among the eight enzymes tested only alanine transaminase (GPT) and phosphoserine aminotransferase (PSAT1) can transaminate glyoxylate with good efficiency, using L-glutamate (and, for GPT, also $\mathrm{L}$-alanine) as the best amino-group donor. These findings confirm that glyoxylate transamination can occur in the cytosol, in direct competition with the conversion of glyoxylate to oxalate. The potential implications for the treatment of primary hyperoxaluria are discussed. 


\section{INTRODUCTION}

Primary hyperoxaluria type $1(\mathrm{PH} 1)$ is an autosomal-recessive inborn disease occurring in 1 per 120,000 live births [1]. It is caused by a deficiency of the enzyme alanine:glyoxylate aminotransferase (AGXT), which normally localizes to the peroxisomes in hepatocytes [1-3]. AGXT uses pyridoxal phosphate (PLP) as a cofactor [4] and catalyzes the nearly-irreversible transfer of the amino group from alanine to glyoxylate, to yield glycine and pyruvate [5, 6] (Figure 1).

In $\mathrm{PH} 1$ patients, glyoxylate cannot be efficiently converted to glycine and is instead oxidized to oxalate, leading to hyperoxalemia and hyperoxaluria. In turn, this causes the deposition of insoluble calcium oxalate in the kidney and in other tissues, leading to nephrolithiasis, nephrocalcinosis, systemic tissue damage and eventually kidney failure $[1,3,7]$.

Since the human organism produces a variety of aminotransferases, and since these enzymes often show a broad substrate specificity [8], it is somewhat surprising that other transaminases may not functionally compensate for the deficiency of AGXT. As a matter of fact, another alanine:glyoxylate aminotransferase (known as AGXT2; [9]) is found in mammalian liver, but this enzyme localizes solely into the mitochondria [10] and from this subcellular compartment it cannot surrogate the function of AGXT. Furthermore, several pre-genomic studies suggest that other enzymes occurring in the liver of mammals can convert glyoxylate to glycine employing amino acids other than alanine as cosubstrates. For example, an aminotransferase that apparently prefers glutamate as amino-group donor has been purified from human liver [11]. Another glyoxylate transaminase that uses preferably aromatic amino acids as cosubstrates has been obtained from the liver of rodents and monkeys [12] while an enzyme with glutamine-glyoxylate transaminase activity was isolated from rat liver [13]. All these activities are attributable to PLP-dependent enzymes, but none of these catalysts has ever been characterized at a molecular level, and their subcellular localization is not known.

Today, the availability of the complete human genome sequence offers an opportunity to clarify the role of different aminotransferases in the metabolism of glyoxylate. The genes coding for aminotransferases can be identified based on homology criteria and their overall number is relatively modest [14]. Understanding which of these gene products can use glyoxylate as an amino-group acceptor would integrate the earlier biochemical literature and perhaps suggest new routes to the treatment of primary hyperoxaluria type 1. In fact, should some aminotransferase prove capable of efficiently converting glyoxylate to glycine, then stimulation of this enzyme (by means of drugs, or simply by providing a dietary supplement of the preferred amino-group donor) could represent a viable therapy to AGXT deficiency.

Herein, we report the cloning and recombinant expression of eight cytosolic aminotransferases and a preliminary assessment of their efficiencies and cosubstrate preferences in the transamination of glyoxylate. 


\section{EXPERIMENTAL}

\section{Enzymes and chemicals}

Recombinant glycine oxidase (GO, EC 1.4.2.19) from Bacillus subtilis was expressed in Escherichia coli and purified as described [15]. The final enzyme preparation showed a specific activity of $\sim 0.7 \mathrm{U} / \mathrm{mg}$ protein on glycine as substrate. Rabbit muscle lactate dehydrogenase (LDH) was purchased from Fluka; malate dehydrogenase from pig heart, glutamate dehydrogenase from bovine liver and horseradish peroxidase were from Sigma. All the chemicals were of the highest commercial purity available.

\section{Molecular cloning}

A plasmid carrying the AGXT coding sequence (NCBI accession n. X53414) was kindly provided by Prof. C.J. Danpure (University College London). Clones of the complete cDNAs for the other aminotransferases were obtained from imaGenes (Berlin, Germany). The full-length coding sequences were PCR-amplified from these clones, using the PfuUltra High Fidelity Taq polymerase (Stratagene) or the Deep Vent DNA polymerase (New England Biolabs). The ID of the clones and the genespecific PCR primers (purchased from MWG Biotech, Ebersberg, Germany) are listed in Table 1. All the primers bore 5'-tails such that the amplification products contained Cpol target sequences (uppercase letters) near to both ends.

A schematic description of the molecular cloning strategy is outlined in Figure 2. Amplicons were blunt-end cloned into an intermediate vector (usually pBlueScript II KS+ [Stratagene] treated with Smal) using published protocols [16]. Ligated plasmids were then transformed into XL1B E. coli cells (Stratagene) and the inserts were sequence-verified. The plasmids were subsequently treated with $\mathrm{Cpol}$, to extract the fragments corresponding to the amplified full-length cDNAs, ready for subcloning into the expression vector pET28-Cpol.

This plasmid is a derivative of pET28 (Novagen) modified to present a single Cpol restriction site in the cloning region, downstream to a sequence encoding a hexahistidine tag (Angelo Bolchi, unpublished; Supplementary Figure 1). Cpol cleaves its target sequence (CGGTCCG/CGGACCG) after the first CG, generating two nonidentical 3' overhangs (GTC on one strand and GAC on the other). Exploiting these features, the Cpol-cleaved fragments were cloned in-frame and directionally into pET28-Cpol.

\section{Heterologous gene expression and protein purification}

The expression vectors carrying the cloned inserts were transformed into BL21-CodonPlus ${ }^{\circledR}$-RIL (Stratagene) or BL21 Star® (Invitrogen) E. coli cells.

The general expression protocol was as follows. A subculture was used to inoculate a flask of broth containing $50 \mu \mathrm{g} / \mathrm{ml}$ kanamycin (for BL21-CodonPlus ${ }^{\circledR}$-RIL cells, also $170 \mu \mathrm{g} / \mathrm{ml}$ chloramphenicol). Bacteria were grown at $37^{\circ} \mathrm{C}$ in vigorous aeration and agitation, until the cell density reached the appropriate value (usually, $\mathrm{OD}_{600 \mathrm{~nm}} \sim 0.6$ ), at which point isopropyl $\beta$-D-1-thiogalactopyranoside was added to a final concentration of $1 \mathrm{mM}$. After further growth of the induced culture, cells were harvested by centrifugation and sonicated. Subsequently, the recombinant proteins present in the soluble lysate fraction were purified by immobilized metal affinity chromatography. The protein fractions were analyzed by gel electrophoresis and 
those fractions with a purity $>90 \%$ were pooled, dialyzed against a buffer containing $4 \mu \mathrm{M}$ PLP and $1 \mathrm{mM}$ dithiothreitol, and stored at $-80{ }^{\circ} \mathrm{C}$.

Details on (i) the culture conditions adopted for the overexpression of individual proteins, (ii) the specific purification procedures used for each protein and (iii) the overall protein yields are provided in the Supplementary Data.

The concentration of each purified recombinant protein was estimated based on the extinction coefficient at $280 \mathrm{~nm}$ calculated by ProtParam (www.expasy.ch/tools/protparam.html). Activity of the recombinant enzymes (when their specific reactions were known) was assessed through established methods (See Supplementary Table 1).

\section{Glycine oxidase (GO) assay}

The kinetics of glycine production were determined by a discontinuous assay based on the use of GO. The principle of the assay is illustrated in Supplementary Figure 2. Briefly, glyoxylate (1-10 mM final concentration) and one or more potential amino-group donors were equilibrated at the desired reaction temperature in $25 \mathrm{mM}$ potassium phosphate, $\mathrm{pH} 7.4$ before starting the reaction with addition of the aminotransferase (0.05-3 $\mu \mathrm{M}$ final concentration).

Aliquots (20 $\mu$ l each) were removed at appropriate intervals, and further reaction was stopped by mixing with $2 \mu$ of $1 \mathrm{M}$ phosphoric acid to reach $\mathrm{pH} \sim 2$. These samples were then heated at $95^{\circ} \mathrm{C}$ for 5 min to completely inactivate the aminotransferase. Each aliquot was subsequently mixed with $178 \mu \mathrm{l}$ of a solution containing Tris- $\mathrm{HCl}$ pH 8.0 (100 mM final concentration), GO (4 $\mu \mathrm{M}$ final, corresponding to about 0.03 units), 3 units of horseradish peroxidase and $1 \mathrm{mM} \mathrm{o-}$ dianisidine, and incubated at $37^{\circ} \mathrm{C}$ for $30 \mathrm{~min}$ (the time required to reach an endpoint). Finally, the mixtures were supplemented with $50 \mu \mathrm{l}$ of sulfuric acid $(7 \mathrm{~N}$ final concentration) to dissolve the occasional precipitates of oxidized $o$-dianisidine and augment the sensitivity of the assay [17], before measuring absorption spectra in the $530 \mathrm{~nm}$ region to quantitate the extent of 0 -dianisidine oxidation.

In parallel, a calibration line was prepared. 2-40 nmoles of glycine (from a 10 $\mathrm{mM}$ standard solution) were added to a reaction mixture containing $1 \mathrm{mM} \mathrm{o-}$ dianisidine, $4 \mu \mathrm{M} \mathrm{GO}, 15$ units/ml horseradish peroxidase, $10 \mathrm{mM}$ phosphoric acid and $100 \mathrm{mM}$ Tris- $\mathrm{HCl} \mathrm{pH} 8.0$ in a final volume of $200 \mu \mathrm{l}$. The reaction mixtures were incubated and treated as above, and the absorbance at $530 \mathrm{~nm}$ vs. the initial amount of glycine was used to generate a calibration line. Control reactions were performed in which glyoxylate and the potential amino-group donors were incubated together, in the absence of transaminases; under these conditions, the amount of spontaneous glyoxylate transamination was negligible.

\section{GO-based assay in a 96-well format}

To screen for the ability of recombinant aminotransferases to produce glycine, using a variety of potential amino-group donors, the GO-based assay was also adapted to a 96-well microtiter format.

In each well, a single aminotransferase $(1 \mu \mathrm{M})$ was incubated with glyoxylate $(4 \mathrm{mM})$ and one or more potential amino-group donors (5-10 mM each) in a total volume of $40 \mu \mathrm{l}$. After 2.5 hours of incubation at $25{ }^{\circ} \mathrm{C}$, the enzymes were inactivated by adding phosphoric acid to a final concentration of $90 \mathrm{mM}(\mathrm{pH} 2)$. Then, the reaction mixtures were supplemented with $180 \mu$ of Tris- $\mathrm{HCl} 200 \mathrm{mM}(\mathrm{pH} 8)$ 
containing glycine oxidase ( $1 \mu \mathrm{M}$ final), peroxidase $(8 \mathrm{units} / \mathrm{ml})$ and dianisidine (1 $\mathrm{mM}$ ) and stored at $37^{\circ} \mathrm{C}$ for one hour. Finally $50 \mu \mathrm{l}$ of sulfuric acid were added to each well and the plate was scanned with an automated plate reader.

Continuous spectrophotometric assays for alanine-glyoxylate, serine-glyoxylate and glutamate-glyoxylate transaminase activities

Alanine-glyoxylate, serine-glyoxylate and glutamate-glyoxylate transamination reactions were measured using a continuous spectrophotometric assay at $220 \mathrm{~nm}$ $[18,19]$. At this wavelength, most $\alpha$-keto acids possess an extinction coefficient about tenfold higher than glyoxylate (Supplementary Figure 3) so that their formation can be easily quantified [18].

Typically the reaction mixture $(0.9 \mathrm{ml}$, final volume) contained $1-150 \mathrm{mM}$ amino acid (L-Glu, L-Ala or L-Ser) and 1-10 mM glyoxylate in $25 \mathrm{mM}$ potassium phosphate at $\mathrm{pH}$ 7.5. Reactions were started by adding the recombinant enzyme, and the increase in absorbance was monitored continuously using a Cary 400 double-beam spectrophotometer (Varian). Initial velocities were calculated graphically and expressed as $\mu$ moles of keto acid product (e.g., pyruvate) formed per minute, per mg of protein. The kinetic data were analyzed using Sigma Plot (Systat Software Inc.).

The kinetics of the glutamate-glyoxylate transamination (catalyzed by, e.g., the enzyme PSAT1) could also be monitored spectrophotometrically by a coupled assay, in which the recombinant enzyme $(0.1-0.5 \mu \mathrm{M})$, glutamate and glyoxylate were incubated in the presence of glutamate dehydrogenase, $\mathrm{NH}_{4}{ }^{+}$and $\mathrm{NADH}$. The reaction mixture $(200 \mu$ final volume) contained $25 \mathrm{mM}$ potassium phosphate $(\mathrm{pH}$ 7.5), $32 \mathrm{mM}$ ammonium acetate, $0.25 \mathrm{mM} \mathrm{NADH}$ and 15 units/ml glutamate dehydrogenase. The disappearance of NADH was monitored at $340 \mathrm{~nm}$.

\section{RESULTS}

Identification, selection and cloning of the aminotransferase genes

An inventory of PLP-dependent enzymes encoded in the human genome [14] reveals 18 genes coding for aminotransferases - eight of which are predicted to localize in mitochondria. However, two arguments suggest that mitochondrial enzymes cannot compensate for the deficiency of peroxisomal AGXT. First, the existence of a mitochondrial AGXT isoenzyme (AGXT2) does not prevent the development of primary hyperoxaluria. Second, it is well known that $\mathrm{PH} 1$ is often caused by mutations that mistarget AGXT from peroxisomes to mitochondria [20, 21]. Even though AGXT retains its catalytic function in the mitochondria, it is metabolically ineffective because it is prevented from acting on the peroxisomal glyoxylate pool [21]. Instead, the glyoxylate produced in the peroxisomes can presumably be exported to the cytosol [22]. Thus, we focused in this study on the nine genes predicted to encode cytosolic transaminases, plus AGXT that was used as a positive control. The list of genes is shown in Table 1.

For all these genes, complete cDNAs were available from the IMAGE consortium; when multiple splice variants of a gene product were documented, we chose to clone the variant encoding the longest polypeptide. The coding sequences for the enzymes were then PCR-amplified from the cDNAs, subcloned, sequenceverified and finally cloned into $E$. coli expression vectors (Figure 2). 
The enzymes were overexpressed as His6-tagged proteins in E. coli cells, and purified by immobilized metal affinity chromatography (see Experimental). In most cases it was possible to obtain a good yield of soluble protein. However, production of the protein corresponding to the gene GOT1L1 encountered several problems: upon induction, multiple overexpressed protein species were detected in the cell lysate, and none of them could be purified by metal affinity chromatography. We thus decided not to pursue further the purification and characterization of this gene product.

The recombinant transaminases were soluble, could bind the PLP cofactor (as shown by their characteristic spectra; Supplementary Figure 4), reacted with potential substrates and could catalyze their specific reactions (when known) at rates comparable to those reported by other researchers (Supplementary Table 1).

\section{Development and validation of an AGXT assay using glycine oxidase and peroxidase} as coupling enzymes

To assess the formation of glycine by the various transaminases, we used a $\mathrm{GO} /$ peroxidase coupling system. GO catalyzes the conversion of glycine to glyoxylate and $\mathrm{H}_{2} \mathrm{O}_{2}[15,23]$. The latter is then used by peroxidase to oxidize 0 dianisidine, yielding an intensely colored product [17] (Supplementary Figure 2).

In principle, the use of GO and peroxidase as indicator enzymes could allow monitoring the on-line formation of Gly by means of a continuous assay. However, in continuous coupled assays, the reaction catalyzed by the indicator enzyme must not be rate-limiting the overall kinetics. This requisite is difficult to meet by $\mathrm{GO}$, which is a rather slow enzyme $\left(\mathrm{k}_{\text {cat }} / \mathrm{K}_{\mathrm{M}} \approx 10^{3} \mathrm{M}^{-1} \mathrm{~s}^{-1}\right.$, under optimal conditions [24]). Hence we resorted to a discontinuous method, which, despite being more cumbersome, is not limited by the rate of the coupled reaction, affords an improved reliability of the assay and provides a much greater flexibility in terms of kinetic conditions that can be explored.

The details of the GO-based assay are given in the Experimental section. For comparison, the rates for glycine formation by recombinant AGXT were determined through this assay and through a continuous assay based on the absorbance change at $220 \mathrm{~nm}$ ( $\alpha$-keto acids production) [18, 19], using the same buffer and substrate concentrations (Table 2 ). The rates obtained through the two methods were virtually identical, validating the use of the GO assay for measuring the kinetics of enzymatic glycine production.

Screening of the recombinant aminotransferases for their ability to use glyoxylate as an amino group acceptor

The GO-based assay was adapted for use in a 96-well microtiter format (see Experimental). In fact, we used this plate assay to screen for the ability of the recombinant enzymes to transaminate glyoxylate, using the standard amino acids as amino-group donors (Figure 3).

Besides AGXT (that was included as the positive control) only two aminotransferases appeared able to produce glycine from glyoxylate to an appreciable extent - namely alanine aminotransferase (GPT) and phosphoserine transaminase (PSAT1). The activity of GPT towards glyoxylate was consistent with the results of pre-genomic studies on the rat liver enzyme [25, 26] and, not unexpectedly, L-Ala and L-Glu were by far the best amino-group donors (Figure 3). 
On the other hand PSAT1 could use several different amino acid cosubstrates. These included acidic amino acids (L-Glu and L-Asp, but also Lhomocysteate) and small neutral amino acids such as L-Ala and L-Ser (Figure 3 and data not shown). A series of control kinetic experiments showed that L-Glu was the preferred amino-group donor both at $25^{\circ} \mathrm{C}$ (Table 3 and data not shown) and at $37^{\circ} \mathrm{C}$ (Supplementary Table 2), consistent with the notion that phosphoserine transaminase uses L-Glu as its standard cosubstrate [27]. In spite of the enzyme's name, phosphoserine was not an efficient amino-group donor (not shown).

A surprising result of the plate assay was the apparent inability of CCBL1 (also known as glutamine transaminase $\mathrm{K}$ ) to act on glyoxylate. This was in contrast with a previous study by Han et al. [28], where the same enzyme was reported to employ quite efficiently glyoxylate as an amino-group acceptor. Nevertheless, the reaction conditions in that earlier study were significantly different from those of our plate assay $\left(45^{\circ} \mathrm{C}\right.$, higher ionic strength and the nonstandard amino acid L-kynurenine used as the amino-group donor). More importantly, the reaction rates estimated in that earlier study were based on a single time-point, collected $10 \mathrm{~min}$ after starting the reaction [28]. When we performed specific kinetic assays on the reaction between phenylalanine, glutamine or methionine and glyoxylate, catalyzed by CCBL1, we observed modest initial transamination rates that declined after a few minutes, coming to a near complete stop well before completion of the reaction (Table 3 and Supplementary Figure 5A). Control experiments showed that the enzyme was not undergoing irreversible inactivation, but rather that it was being strongly inhibited by the keto acid products of the reaction (Supplementary Figure 5B and data not shown).

Reactions of GPT and PSAT1 with glyoxylate

We investigated in more detail the activity of GPT and PSAT1 towards glyoxylate. To this end, we measured the reaction rates of the two enzymes as a function of glyoxylate concentration, either in the presence of L-Ala (for GPT only; Figure 4A) or L-Glu (for both enzymes; Figure 4B-C). In these experiments the reaction conditions were chosen to approximate the intracellular environment (potassium phosphate buffer, $\mathrm{pH} 7.4,37^{\circ} \mathrm{C}$ ) and even the concentrations of aminogroup donors employed ( 1 to $5-10 \mathrm{mM}$ ) represented rough lower and upper limits for the cytosolic concentration of L-Ala and L-Glu [29, 30].

GPT transaminated glyoxylate with higher efficiency. Reaction rates changed little when the concentration of L-Ala or L-Glu was raised from 1 to $5 \mathrm{mM}$, implying that GPT was essentially saturated by the amino-group donors at $1 \mathrm{mM}$

concentrations. The apparent specificity constant, $\mathrm{k}_{\text {cat }} / \mathrm{K}_{\mathrm{M}}^{\text {Glyoxylate }}$, fell in all cases in the range $6000-10000 \mathrm{M}^{-1} \mathrm{~s}^{-1}$ (as it can be calculated from the data in Figure 4A-B, based on a molecular mass of $57 \mathrm{kDa}$ for recombinant GPT).

PSAT1 was comparatively less efficient, even though its maximum activity (3.5 umoles $\mathrm{min}^{-1} \mathrm{mg}^{-1}$, corresponding to a turnover number of about $2.5 \mathrm{~s}^{-1}$ ) was just fivefold less than the activity of PSAT1 toward its 'physiological' substrate couple, glutamate-phosphohydroxypyruvate. The apparent specificity constant doubled (from 900 to $1800 \mathrm{M}^{-1} \mathrm{~s}^{-1}$ ) when L-Glu was raised from 1 to $10 \mathrm{mM}$, suggesting that PSAT1 was not fully saturated at the lowest L-Glu concentration tested. However, a further increase in glutamate concentration (to $20 \mathrm{mM}$ ) slightly depressed the apparent $\mathrm{k}_{\text {cat }} / \mathrm{K}_{\mathrm{M}}^{\text {Glyoxylate }}$, possibly due to substrate inhibition (not shown). 


\section{DISCUSSION}

We have expressed in E. coli eight cytosolic aminotransferases, plus the peroxisomal alanine:glyoxylate aminotransferase. For some of these human enzymes, overproduction by recombinant means had already been described [28, 32-35]. For others (GOT1, AGXT2L1 and AGXT2L2) this is the first report of cloning and recombinant expression in bacteria. In the long term, the recombinant expression of all human transaminases will allow the production of enzyme arrays useful for a synoptic analysis of the respective contributions to metabolic pathways, for quick comparisons of substrate specificities and for the screening of selective inhibitors. Furthermore, aminotransferases are also important tools in biocatalysis, e.g. for the deracemization of natural and non-proteinogenic a-amino acids [36].

\section{An assay for glycine-forming transaminases}

The specific goal of this study was the identification of aminotransferases that use glyoxylate as a substrate. To this end, we have devised a method for detecting the formation of glycine - a method whereby multiple potential amino-group donors can be tested simultaneously and where separation of the products from the substrates is not required. In fact, while GO is active on glycine and on a few Damino acids, as well as on some primary and secondary amines (such as sarcosine), L-amino acids are neither good substrates nor inhibitors of this flavoenzyme [15].

In the past, several assays have been used to monitor the reactions catalyzed by transaminases that use glyoxylate [37]. Early methods were based (like the GO assay we developed) on the quantitation of the glycine produced [38]. However, these techniques were laborious and often unreliable, so that most researchers turned instead to assays for the quantitation of the keto acid co-product (e.g., pyruvate for the AGXT reaction) [37].

The most accurate and sensitive of these methods entail the derivatization of the keto acid product with some phenylhydrazine dye, followed by HPLC separation and quantitation (e.g., see [6]). These assays however require specific equipment and instrumental setup, and are difficult to apply to large-scale screenings.

The continuous assays based on the differential absorbance of glyoxylate versus other keto acids at $\sim 220 \mathrm{~nm}$ are simple and reasonably accurate, provided that the extinction coefficient of the specific keto acid product is known [18]. A major limit of the method is the need to work at a wavelength where most substances absorb, thus affecting the sensitivity of the assay.

Finally, continuous coupled assays based on dehydrogenases (e.g., malate dehydrogenase to monitor the formation of oxaloacetate) are very convenient to study the kinetics of specific transamination reactions and can be easily employed in large-scale screenings. However, these assays are not general, since detection of different keto acid products requires the use of different coupling enzymes.

Additionally, some dehydrogenases can use glyoxylate as a substrate, complicating the kinetic analysis [39].

\section{Cytosolic transaminases that act on glyoxylate}

The glycine oxidase assay could be adapted to a 96-well format, and was used to screen our set of recombinant aminotransferases (as well as libraries of potential amino-group donors). Notably, only PSAT1 and GPT, out of the eight enzymes tested, could transaminate glyoxylate to glycine with substantial efficiency. 
The two homologs of the mitochondrial AGXT (AGXT2L1 and AGXT2L2) would not produce glycine using any standard amino acid as a co-substrate. Preliminary results suggest that these proteins are indeed transaminases, but they appear to strongly prefer pyruvate as the amino group acceptor. Studies are underway to elucidate the reaction preferences of these enzymes.

To our knowledge, the activity of PSAT1 on glyoxylate has never been described before. The observation that the most efficient amino-group donor for this enzyme was L-Glu, led us to consider the identification of PSAT1 with a glutamateglyoxylate transaminase partially purified from human liver by Thompson and Richardson, over 40 years ago [11]. The enzyme studied by those authors reportedly showed a $\mathrm{K}_{\mathrm{M}}^{\text {Glyoxylate }}=2 \mathrm{mM}$ [11], similar to the one observed by us with PSAT1 (Figure $4 C$ ). However, the enzyme from human liver was unable to use L-Ser as an amino-group donor, while it was very active with L-Ala [11]. Based on these considerations, it is most likely that the enzyme partially purified by Thompson and Richardson was GPT.

\section{Implications for glyoxylate metabolism}

The results of this paper help integrate the current view of the cytosolic metabolism of glyoxylate. It is well appreciated that, in the hepatocyte cytosol, glyoxylate can be oxidized to oxalate by lactic dehydrogenase (LDH) or reduced to glycolate by glyoxylate reductase/hydroxypyruvate reductase (GRHPR) [40, 41]. Oxalate is a dead-end product of the metabolism, as it can only be excreted and eliminated, mainly through the kidney. Glycolate can also be excreted; otherwise, it may enter the peroxisomes and be reconverted to glyoxylate [22], which would establish a sort of futile cycle.

We have confirmed a third fate for cytosolic glyoxylate, namely its conversion to glycine, carried out by GPT and PSAT1 (and, to a much lesser extent, by CCBL1) (Figure 5). This transamination reaction is virtually irreversible $[6,11]$, and has the advantage of producing a substance that the cell can readily incorporate into proteins or utilize in many biosynthetic pathways.

The actual importance of glyoxylate transamination, relative to the first two metabolic routes, remains to be established. The apparent $\mathrm{k}_{\text {cat }} / \mathrm{K}_{\mathrm{M}}^{\text {Glyoxylate }}$ values (mirroring catalytic performance at low glyoxylate concentrations) for GPT and PSAT1 fall in the $10^{3}-10^{4} \mathrm{M}^{-1} \mathrm{~S}^{-1}$ range (Figure 4), which is lower than the values reported for LDH $\left(3 \times 10^{4}\right.$ to $\left.10^{5} \mathrm{M}^{-1} \mathrm{~s}^{-1}\right)$ and GRHPR $\left(6 \times 10^{4}\right.$ to $\left.1.1 \times 10^{5} \mathrm{M}^{-1} \mathrm{~s}^{-1}\right)$ [40]. In vivo, however, the partitioning of cytosolic glyoxylate between oxidation, reduction and transamination will depend on several factors that may outweigh the intrinsic efficiencies of the individual catalysts. Such factors include the availability of specific coenzymes and cosubstrates (e.g., NADPH, PLP, L-Glu), the presence of inhibitors (e.g., keto acids that compete with glyoxylate) and above all the cytosolic concentration of the different enzymes, which in turn will depend on their relative expression levels.

\section{Potential implications for the treatment of hyperoxaluria}

It is believed that the excess oxalate produced in $\mathrm{PH} 1$ is formed mostly in the hepatocyte cytosol, via the LDH-catalyzed reaction [2, 42]. This implies that cytosolic transaminases are inefficient at competing with LDH for the common substrate, glyoxylate, released by the peroxisomes. However if expression of the genes GPT 
and PSAT1 were increased substantially above normal, this should steer more and more glyoxylate toward transamination - perhaps enough to significantly diminish oxalate production and the symptoms that ensue.

Are there practical ways to stimulate the expression of GPT and PSAT1, so as to test the above hypothesis? It is known that GPT expression is induced by corticosteroids - indeed, the gene promoter includes a glucocorticoid response element - and by prescription drugs such as the hypolipidemic compound fenofibrate [43]. As for PSAT1, its expression in hepatocytes seems highly regulated and may be strongly influenced by nutritional factors. For example, a survey of the data available at GEO profiles (http://www.ncbi.nlm.nih.gov) suggests that PSAT1 in the mouse liver is highly induced by a ketogenic regimen (i.e., a diet based on fats and proteins, but low in carbohydrates) [44].

The possibility that off-the-shelf drugs and dietary changes may help manage $\mathrm{PH} 1$, while admittedly speculative, seems worth being explored. Since transgenic mice exist which recapitulate the metabolic defect of $\mathrm{PH} 1$ [45], it could be relatively straightforward to test whether treatments that augment the expression of GPT and PSAT1 can decrease oxalate excretion in these animal models. Such studies would provide a better understanding of oxalate production in vivo and, in the best scenario, offer concrete suggestions for the therapy of genetic hyperoxaluria.

\section{FUNDING}

The financial support of Telethon-Italy (grant GGP06183) is gratefully acknowledged. Parts of this work were also supported by a FAR (Fondo di Ateneo per la Ricerca) grant to L. Pollegioni and by a grant from the Italian Ministry of Research (COFIN 2007).

\section{ACKNOWLEDGEMENTS}

We are indebted with Andrea Mozzarelli, Simone Ottonello and Angelo Bolchi for support, as well as with Filippo Monica, Francesca Passeri and Francesca Donati for technical assistance. 


\section{REFERENCES}

1 Cochat, P. (1999) Primary hyperoxaluria type 1. Kidney Int. 55, 2533-2547

2 Danpure, C. J. (2004) Molecular aetiology of primary hyperoxaluria type 1. Nephron Exp. Nephrol. 98, e39-44

3 Coulter-Mackie, M. B. and Rumsby, G. (2004) Genetic heterogeneity in primary hyperoxaluria type 1: impact on diagnosis. Mol. Genet. Metab. 83, 3846

4 Zhang, X., Roe, S. M., Hou, Y., Bartlam, M., Rao, Z., Pearl, L. H. and Danpure, C. J. (2003) Crystal structure of alanine:glyoxylate aminotransferase and the relationship between genotype and enzymatic phenotype in primary hyperoxaluria type 1. J. Mol. Biol. 331, 643-652

5 Thompson, J. S. and Richardson, K. E. (1967) Isolation and characterization of an L-alanine: glyoxylate aminotransferase from human liver. J. Biol. Chem. 242, 3614-3619

6 Cellini, B., Bertoldi, M., Montioli, R., Paiardini, A. and Borri Voltattorni, C. (2007) Human wild-type alanine:glyoxylate aminotransferase and its naturally occurring G82E variant: functional properties and physiological implications. Biochem. J. 408, 39-50

7 Danpure, C. J. (2005) Molecular etiology of primary hyperoxaluria type 1: new directions for treatment. Am. J. Nephrol. 25, 303-310

8 Mehta, P. K. and Christen, P. (2000) The molecular evolution of pyridoxal-5'phosphate-dependent enzymes. Adv. Enzymol. 74, 129-184

9 Lee, I. S., Muragaki, Y., Ideguchi, T., Hase, T., Tsuji, M., Ooshima, A., Okuno, E. and Kido, R. (1995) Molecular cloning and sequencing of a cDNA encoding alanine-glyoxylate aminotransferase 2 from rat kidney. J. Biochem. 117, 856862

10 Takada, Y. and Noguchi, T. (1982) Subcellular distribution, and physical and immunological properties of hepatic alanine: glyoxylate aminotransferase isoenzymes in different mammalian species. Comp. Biochem. Physiol. B 72, 597-604

11 Thompson, J. S. and Richardson, K. E. (1966) Isolation and characterization of a glutamate-glycine transaminase from human liver. Arch. Biochem. Biophys. 117, 599-603

12 Harada, I., Noguchi, T. and Kido, R. (1978) Purification and characterization of aromatic-amino-acid-glyoxylate aminotransferase from monkey and rat liver. Hoppe Seylers Z. Physiol. Chem. 359, 481-488

13 Cooper, J. L. and Meister, A. (1972) Isolation and properties of highly purified glutamine transaminase. Biochemistry 11, 661-671

14 Percudani, R. and Peracchi, A. (2003) A genomic overview of pyridoxalphosphate-dependent enzymes. EMBO Rep. 4, 850-854

15 Job, V., Molla, G., Pilone, M. S. and Pollegioni, L. (2002) Overexpression of a recombinant wild-type and His-tagged Bacillus subtilis glycine oxidase in Escherichia coli. Eur. J. Biochem. 269, 1456-1463

16 Bolchi, A., Ottonello, S. and Petrucco, S. (2005) A general one-step method for the cloning of PCR products. Biotechnol. Appl. Biochem. 42, 205-209

17 Washko, M. E. and Rice, E. W. (1961) Determination of glucose by an improved enzymatic procedure. Clin. Chem. 7, 542-545 
18 Porter, D. J., Harrington, J. A., Almond, M. R., Chestnut, W. G., Tanoury, G. and Spector, T. (1995) Enzymatic elimination of fluoride from $\alpha$-fluoro- $\beta$ alanine. Biochem. Pharmacol. 50, 1475-1484

19 Cooper, A. J., Krasnikov, B. F., Okuno, E. and Jeitner, T. M. (2003) L-alanineglyoxylate aminotransferase II of rat kidney and liver mitochondria possesses cysteine S-conjugate $\beta$-lyase activity: a contributing factor to the nephrotoxicity/hepatotoxicity of halogenated alkenes? Biochem. J. 376, 169178

20 Danpure, C. J., Cooper, P. J., Wise, P. J. and Jennings, P. R. (1989) An enzyme trafficking defect in two patients with primary hyperoxaluria type 1 . peroxisomal alanine/glyoxylate aminotransferase rerouted to mitochondria. J. Cell Biol. 108, 1345-1352

21 Danpure, C. J., Lumb, M. J., Birdsey, G. M. and Zhang, X. (2003) Alanine:glyoxylate aminotransferase peroxisome-to-mitochondrion mistargeting in human hereditary kidney stone disease. Biochim. Biophys. Acta 1647, 70-75

22 Baker, P. R., Cramer, S. D., Kennedy, M., Assimos, D. G. and Holmes, R. P. (2004) Glycolate and glyoxylate metabolism in HepG2 cells. Am. J. Physiol. Cell. Physiol. 287, C1359-C1365

23 Job, V., Marcone, G. L., Pilone, M. S. and Pollegioni, L. (2002) Glycine oxidase from Bacillus subtilis. Characterization of a new flavoprotein. J. Biol. Chem. 277, 6985-6993

24 Molla, G., Motteran, L., Job, V., Pilone, M. S. and Pollegioni, L. (2003) Kinetic mechanisms of glycine oxidase from Bacillus subtilis. Eur. J. Biochem. 270, 1474-1482

25 Noguchi, T., Takada, Y. and Kido, R. (1977) Glutamate-glyoxylate aminotransferase in rat liver cytosol. Purification, properties and identity with alanine-2-oxoglutarate aminotransferase. Hoppe Seylers Z. Physiol. Chem. 358, 1533-1542

26 Kobayashi, S., Hayashi, S., Fujiwara, S. and Noguchi, T. (1989) Identity of alanine:glyoxylate aminotransferase with alanine:2-oxoglutarate aminotransferase in rat liver cytosol. Biochimie 71, 471-475

27 Hirsch, H. and Greenberg, D. M. (1967) Studies on phosphoserine aminotransferase of sheep brain. J. Biol. Chem. 242, 2283-2287

28 Han, Q., Li, J. and Li, J. (2004) pH dependence, substrate specificity and inhibition of human kynurenine aminotransferase I. Eur. J. Biochem. 271, 4804-4814

29 Fafournoux, P., Remesy, C. and Demigne, C. (1983) Control of alanine metabolism in rat liver by transport processes or cellular metabolism.

Biochem. J. 210, 645-652

30 Geerts, W. J., Jonker, A., Boon, L., Meijer, A. J., Charles, R., Van Noorden, C. $\mathrm{J}$. and Lamers, W. H. (1997) In situ measurement of glutamate concentrations in the periportal, intermediate, and pericentral zones of rat liver. J. Histochem. Cytochem. 45, 1217-1229

31 Meany, J. E. and Pocker, Y. (1991) The dehydration of glyoxalate hydrate: general-acid, general-base, metal ion and enzymic catalysis. J. Am. Chem. Soc. 113, 6155-6161

32 Davoodi, J., Drown, P. M., Bledsoe, R. K., Wallin, R., Reinhart, G. D. and Hutson, S. M. (1998) Overexpression and characterization of the human 
mitochondrial and cytosolic branched-chain aminotransferases. J. Biol. Chem. 273, 4982-4989

33 Sivaraman, S. and Kirsch, J. F. (2006) The narrow substrate specificity of human tyrosine aminotransferase-the enzyme deficient in tyrosinemia type II. FEBS J. 273, 1920-1929

34 Baek, J. Y., Jun, D. Y., Taub, D. and Kim, Y. H. (2003) Characterization of human phosphoserine aminotransferase involved in the phosphorylated pathway of L-serine biosynthesis. Biochem. J. 373, 191-200

35 Liu, L., Zhong, S., Yang, R., Hu, H., Yu, D., Zhu, D., Hua, Z., Shuldiner, A. R., Goldstein, R., Reagan, W. J. and Gong, D. W. (2008) Expression, purification, and initial characterization of human alanine aminotransferase (ALT) isoenzyme 1 and 2 in High-five insect cells. Protein Expr. Purif. 60, 225-231

36 Tessaro, D., Molla, G., Pollegioni, L. and Servi, S. (2009) Chemo-enzymatic deracemization methods. in Modern biocatalysis (Fessner, W.-D. and Anthonsen, T., eds.), pp. 195-228, Wiley-VCH Weinheim

37 Rowsell, E. V., Carnie, J. A., Snell, K. and Taktaka, B. (1972) Assays for glyoxylate aminotransferase activities. Int. J. Biochem. 3, 247-257

38 Alexander, B., Landwehr, G. and Seligman, A. M. (1945) A specific micromethod for the colorimetric determination of glycine in blood and urine. J. Biol. Chem. 160, 51-59

39 Thompson, J. S. and Richardson, K. E. (1968) Determination of pyruvate in enzyme-catalyzed reactions in the presence of glyoxylate. Anal. Biochem. 24, 197-201

40 Mdluli, K., Booth, M. P., Brady, R. L. and Rumsby, G. (2005) A preliminary account of the properties of recombinant human Glyoxylate reductase (GRHPR), LDHA and LDHB with glyoxylate, and their potential roles in its metabolism. Biochim. Biophys. Acta 1753, 209-216

41 Behnam, J. T., Williams, E. L., Brink, S., Rumsby, G. and Danpure, C. J. (2006) Reconstruction of human hepatocyte glyoxylate metabolic pathways in stably transformed Chinese-hamster ovary cells. Biochem. J. 394, 409-416

42 Murray, M. S., Holmes, R. P. and Lowther, W. T. (2008) Active site and loop 4 movements within human glycolate oxidase: implications for substrate specificity and drug design. Biochemistry 47, 2439-49

43 Thulin, P., Rafter, I., Stockling, K., Tomkiewicz, C., Norjavaara, E., Aggerbeck, M., Hellmold, H., Ehrenborg, E., Andersson, U., Cotgreave, I. and Glinghammar, B. (2008) PPAR $\alpha$ regulates the hepatotoxic biomarker alanine aminotransferase (ALT1) gene expression in human hepatocytes. Toxicol. Appl. Pharmacol. 231, 1-9

44 Kennedy, A. R., Pissios, P., Otu, H., Xue, B., Asakura, K., Furukawa, N., Marino, F. E., Liu, F. F., Kahn, B. B., Libermann, T. A., Maratos-Flier, E. and Roberson, R. (2007) A high-fat, ketogenic diet induces a unique metabolic state in mice. Am. J. Physiol. Endocrinol. Metab. 292, E1724-E1739

45 Salido, E. C., Li, X. M., Lu, Y., Wang, X., Santana, A., Roy-Chowdhury, N., Torres, A., Shapiro, L. J. and Roy-Chowdhury, J. (2006) Alanine-glyoxylate aminotransferase-deficient mice, a model for primary hyperoxaluria that responds to adenoviral gene transfer. Proc. Natl. Acad. Sci. U.S.A. 103, $18249-18254$ 


\section{FIGURE LEGENDS}

Fig. 1. The reaction catalyzed by aminotransferases that use glyoxylate as an amino-group acceptor, producing glycine. For AGXT, the second substrate (amino-group donor) is L-alanine and the second product is pyruvate.

Fig. 2. Overview of the general procedure adopted for the molecular cloning and recombinant expression of human aminotransferase genes.

Fig. 3: A plate assay for the ability of recombinant aminotransferases to produce glycine from glyoxylate. Each well contained the indicated amino acids (10 $\mathrm{mM}$ each, except for aromatic amino acids that were $5 \mathrm{mM})$, glyoxylate $(4 \mathrm{mM})$ and the specified transaminase $(1 \mu \mathrm{M})$. The transamination reactions were allowed to proceed for 2.5 hours before testing for the formation of glycine (see Experimental).

Fig. 4: Rates of the glyoxylate transaminations catalyzed by GPT and PSAT1, as a function of substrate concentration. Reactions were carried out at $37^{\circ} \mathrm{C}$, in $25 \mathrm{mM}$ potassium phosphate, and monitored by following the change in absorbance at $220 \mathrm{~nm}$. Data were fitted to Michaelis-Menten hyperbolas. (A) Reaction of GPT with L-alanine as the amino-group donor. The titrations collected at $1 \mathrm{mM}$ and $5 \mathrm{mM} \mathrm{L-Ala} \mathrm{yielded} \mathrm{similar} V_{\max }$ values (5.7 and $7.2 \mu$ moles $\mathrm{min}^{-1} \mathrm{mg}^{-1}$, respectively) and similar apparent $\mathrm{K}_{\mathrm{M}}^{\text {Glyoxylate }}$ values (1 and $0.8 \mathrm{mM}$, respectively). (B) Reaction of GPT with L-glutamate as the donor. The titrations collected at $1 \mathrm{mM}$ and $5 \mathrm{mM} \mathrm{L}$-Glu were practically undistinguishable. $V_{\max }=6.7 \mu$ moles $\mathrm{min}^{-1} \mathrm{mg}^{-1}$ and $\mathrm{K}_{\mathrm{M}}^{\text {Glyoxylate }}=0.75 \mathrm{mM}$. (C) Reaction of PSAT1 with L-glutamate as the amino-group donor. The catalytic parameters were: $\mathrm{V}_{\max }=3.5 \mu$ moles $\mathrm{min}^{-1} \mathrm{mg}^{-1}$ and $\mathrm{K}_{\mathrm{M}}^{\text {Glyoxylate }}=5.5$ $\mathrm{mM}(1 \mathrm{mM} \mathrm{L-Glu}) ; \mathrm{V}_{\max }=3.6 \mu$ moles $\mathrm{min}^{-1} \mathrm{mg}^{-1}$ and $\mathrm{K}_{\mathrm{M}}^{\text {Glyoxylate }}=2.7 \mathrm{mM}(10 \mathrm{mM} \mathrm{L}$ Glu). The relatively high $\mathrm{K}_{\mathrm{M}}^{\text {Glyoxylate }}$ values may mirror the fact that the carbonyl group of glyoxylate is $>95 \%$ hydrated to the gem diol form in neutral aqueous solution [31].

Fig. 5: Metabolic fates available to glyoxylate in the cytosol of hepatocytes. GRHPR indicates glyoxylate reductase/hydroxypyruvate reductase. $\mathrm{LDH}$ is lactate dehydrogenase. Examination of the NCBI EST profile database (http:// www.ncbi.nlm.nih.gov/unigene) suggests that LDH isozymes are normally expressed in the liver at higher levels than GRHPR, GPT or PSAT1. 
Table 1: cDNAs corresponding to the aminotransferases cloned in this study

\begin{tabular}{|c|c|c|c|}
\hline Gene $^{*}$ & EST Clone ID & PCR primers ${ }^{\dagger}$ & $\begin{array}{l}\text { Protein } \\
\text { size }(a a)^{\ddagger}\end{array}$ \\
\hline$A G X T^{\S}$ & - & $\begin{array}{ll}\text { FW: } & \text { atCGGTCCGatggcctctcacaagctgctg } \\
\text { RE: } & \text { taCGGACCGtcacagcttcttcttggggc }\end{array}$ & 415 \\
\hline AGXT2L1 & IMAGE 4797767 & $\begin{array}{l}\text { FW: atCGGTCCGatgtgcgagctgtacagtaagc } \\
\text { RE: atCGGACCGatcttgctttaaaatgcaaatcag }\end{array}$ & 522 \\
\hline AGXT2L2 & IMAGE 5220434 & $\begin{array}{l}\text { FW: atCGGTCCGatggccgcagaccagcgc } \\
\text { RE: atCGGACCGtaggcagagcagggctggc }\end{array}$ & 473 \\
\hline$B C A T 1$ & DKFZp686E12175Q & $\begin{array}{l}\text { FW: atCGGTCCGatggattgcagtaacggatgc } \\
\text { RE: taCGGACCGttccattgtatcctctatttcc }\end{array}$ & 408 \\
\hline CCBL1 & IMAGE $4137942^{\|}$ & $\begin{array}{l}\text { FW: atCGGTCCGatggccaaacagctgcaggc } \\
\text { RE: taCGGACCGccaaggcgtgacttcaggg }\end{array}$ & 445 \\
\hline GOT1 & IMAGE 2820849 & $\begin{array}{l}\text { FW: atCGGTCCGatggcacctccgtcagtctttg } \\
\text { RE: } \text { taCGGACCGtactggacgggtggtgtttc }\end{array}$ & 436 \\
\hline GOT1L1 & IMAGE 5273324 & $\begin{array}{l}\text { FW: atCGGTCCGatgcccaccctttcagtgttc } \\
\text { RE: atCGGACCGttgcaaagactaaagtttattcca }\end{array}$ & 444 \\
\hline GPT & IMAGE 4179699 & $\begin{array}{l}\text { FW: atCGGTCCGatggcctcgagcacaggtg } \\
\text { RE: } \text { taCGGACCGccagcctggccccagctg }\end{array}$ & 519 \\
\hline PSAT1 & IMAGE 3883843 & $\begin{array}{l}\text { FW: atCGGTCCGatggacgcccccaggcag } \\
\text { RE: taCGGACCGagtatatcctggttaggatgtg }\end{array}$ & 393 \\
\hline TAT & IMAGE 40146565 & $\begin{array}{ll}\text { FW: } & \text { atCGGTCCGatggacccatacatgattcag } \\
\text { RE: } & \text { taCGGACCGtcaggagaatggatgcaggc }\end{array}$ & 477 \\
\hline
\end{tabular}

* AGXT encodes the peroxisomal alanine-glyoxylate aminotransferase. AGXT2L1 and AGXT2L2 encode two homologs (presumably cytosolic) of AGXT2 (the mitochondrial alanine-glyoxylate aminotransferase). BCAT1 encodes the cytosolic branched-chain amino acid transaminase. CCBL1 (official HUGO Gene Nomenclature Committee symbol) encodes a cytosolic, promiscuous enzyme known by different names: glutamine transaminase K, kynurenine aminotransferase I and cysteine-conjugate $\beta$-lyase I. GOT1 encodes the cytosolic aspartate aminotransferase. GOT1L1 encodes a GOT1 homolog. GPT encodes the cytosolic alanine transaminase. PSAT1 encodes phosphoserine aminotransferase. TAT encodes the cytosolic tyrosine aminotransferase.

${ }^{\dagger}$ Forward primers were designed to introduce a Cpol restriction site (uppercase letters) just before the start codon of the coding sequence (underlined). Reverse primers were usually designed to pair with the 5'-UTR of the cDNAs; however, when such sequence was unknown or too short, the primers were designed to pair with the 5 '-end of the coding sequence, including the stop codon (doubly-underlined).

₹ The length reported here refers to the recombinant protein, which includes a 23-aa Nterminal tail encompassing a hexahistidine tag.

$\S$ A vector containing the complete coding sequence of $A G X T$ was kindly provided by Dr. C. J. Danpure (University College London).

$\|$ Before subcloning in the expression vector, the cDNA contained in this EST clone was manipulated to remove a small intervening sequence and an internal Cpol restriction site. 
Table 2: Comparing the reaction rates of AGXT measured through the GO assay or through a continuous spectrophotometric assay ( $\alpha$-keto acids formation)

\begin{tabular}{|c|c|c|c|c|}
\hline \multirow{2}{*}{$\begin{array}{l}\text { Glyoxylate } \\
\text { (mM) }\end{array}$} & \multirow{2}{*}{$\begin{array}{l}\text { L-Ala } \\
\text { (mM) }\end{array}$} & \multirow{2}{*}{$\begin{array}{l}\text { L-Ser } \\
\text { (mM) }\end{array}$} & \multicolumn{2}{|c|}{$\begin{array}{c}\text { Activity } \\
\left(\mu \mathrm{mol} \mathrm{min}^{-1} \mathrm{mg}^{-1}\right)\end{array}$} \\
\hline & & & GO assay & Abs $220 \mathrm{~nm}$ assay \\
\hline 10 & 2 & & $1.3 \pm 0.2$ & $1.5 \pm 0.3$ \\
\hline 10 & 10 & & $7.9 \pm 2.3$ & $6.9 \pm 1.6$ \\
\hline 10 & 150 & & $15.9 \pm 1.5$ & $17.8 \pm 0.5$ \\
\hline 2 & 10 & & $6.4 \pm 0.2$ & $5.5 \pm 0.4$ \\
\hline 10 & & 10 & $0.7 \pm 0.2$ & $0.6 \pm 0.3$ \\
\hline
\end{tabular}

Reactions were measured in $25 \mathrm{mM}$ potassium phosphate buffer $(\mathrm{pH} 7.4)$ at $25^{\circ} \mathrm{C}$. The reported activity values represent the average of at least two independent determinations. 
Table 3: Glycine-forming activities of the recombinant aminotransferases, using selected amino-group donors

\begin{tabular}{|c|c|c|c|}
\hline \multirow[t]{2}{*}{ Enzyme } & \multirow[t]{2}{*}{ Amino-group donor } & \multicolumn{2}{|c|}{$\begin{array}{c}\text { Activity } \\
\left(\mu \mathrm{mol} \mathrm{min}^{-1} \mathrm{mg}^{-1}\right)\end{array}$} \\
\hline & & $1 \mathrm{mM}$ donor & $10 \mathrm{mM}$ donor \\
\hline AGXT & L-Ala & 1 & 6.8 \\
\hline \multirow[t]{2}{*}{ AGXT2L1 } & L-Ala & $<0.006$ & $<0.006$ \\
\hline & $\beta$-alanine* & $<0.006$ & $<0.006$ \\
\hline \multirow[t]{2}{*}{ AGXT2L2 } & L-Ala & $<0.006$ & $<0.006$ \\
\hline & $\beta$-alanine* & $<0.006$ & $<0.006$ \\
\hline \multirow[t]{2}{*}{ BCAT1 } & L-Glu & $<0.006$ & $<0.006$ \\
\hline & L-Ile & $<0.006$ & $<0006$ \\
\hline \multirow[t]{2}{*}{$\mathrm{CCBL}^{\dagger}$} & L-Gln & $(0.13)$ & $(0.17)$ \\
\hline & $\begin{array}{l}\text { L-Phe } \\
\text { L-Met }\end{array}$ & $\begin{array}{l}(0.10) \\
(0.26)\end{array}$ & $\begin{array}{c}(0.13)^{\ddagger} \\
(0.3)\end{array}$ \\
\hline \multirow[t]{2}{*}{ GOT1 } & L-Glu & $<0.006$ & $<0.006$ \\
\hline & L-Asp & $<0.006$ & $<0.006$ \\
\hline \multirow[t]{3}{*}{ GPT } & L-Glu & 2.2 & 2.5 \\
\hline & L-Gln & -7 & $<0.006$ \\
\hline & L-Ala & 1.7 & 2.1 \\
\hline \multirow[t]{5}{*}{ PSAT1 } & L-Glu & 1.5 & 1.1 \\
\hline & L-GIn & - & 0.01 \\
\hline & L-Asp & 0.02 & 0.15 \\
\hline & L-Ala & 0.02 & 0.16 \\
\hline & -Ser & 0.03 & 0.13 \\
\hline \multirow[t]{2}{*}{ TAT } & T & $<0.006$ & $<0.006$ \\
\hline & & $<0.006$ & $<0.006$ \\
\hline
\end{tabular}

The concentration of glyoxylate was $4 \mathrm{mM}$ in all cases. Activities were measured in $25 \mathrm{mM}$ potassium phosphate buffer $(\mathrm{pH} 7.4)$ at $25^{\circ} \mathrm{C}$, using either the continuous assay at $220 \mathrm{~nm}$ or the GO-based assay. Upper limits are given for several enzymes that, at a $1 \mu \mathrm{M}$ concentration, failed to yield a detectable amount of glycine in six hours (i.e., they formed less than $100 \mu \mathrm{M}$ glycine, the minimum amount measurable in our GO assay setup).

* $\beta$-alanine was tested as a potential substrate for AGXT2L1 and AGXT2L2 since the homologous enzyme AGXT2 is known to transaminate this amino acid. 
${ }^{\dagger}$ The activities of CCBL1 (glutamine transaminase K) with L-Phe, L-Gln and L-Met were calculated based on the first few minutes of the kinetics, after which time the reaction rates slowed down substantially. See Supplementary Figure 5.

₹ This reaction rate was measured at $5 \mathrm{mM} \mathrm{L}$-Phe. 


\section{Figure 1}<smiles>O=CC(=O)[O-]</smiles><smiles>[R][C@@H]([NH3+])C(=O)[O-]</smiles><smiles>CCCCC([NH3+])C(=O)[O-]</smiles><smiles>[R]C(=O)C(=O)[O-]</smiles>
Glyoxylate
Glycine
$\mathbf{R}=\mathrm{CH}_{3}$
L-Alanine

\section{Pyruvate}


Figure 2

\section{Full-length cDNA clones}

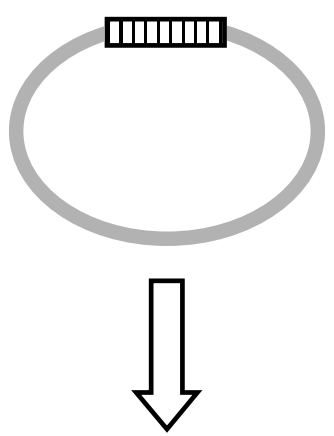

PCR Amplification
(Cpol-tailed primers)

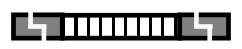
$\sqrt[\begin{array}{l}\text { Blunt subcloning in } \\ \text { intermediate vector }\end{array}]{ }$
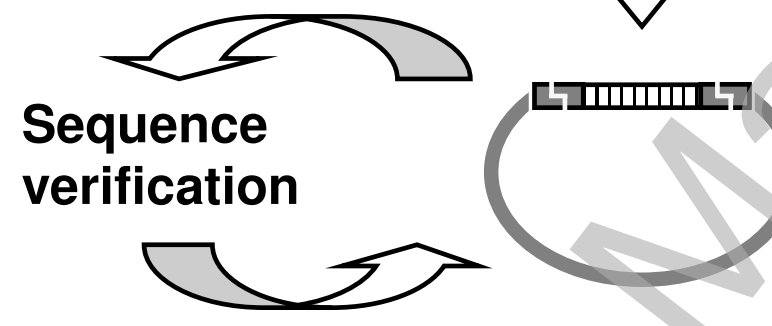

Subcloning in pET28-Cpol

\section{Protein expression and purification}


Figure 3

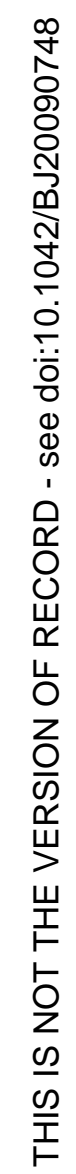

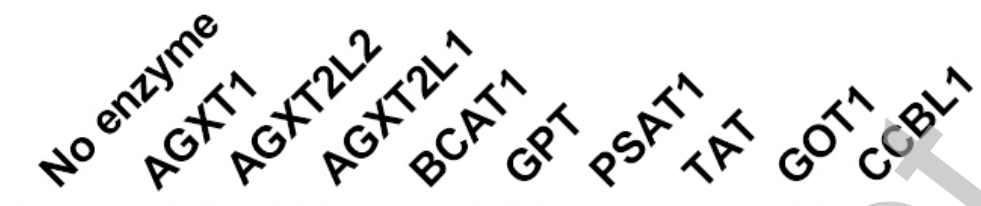

L-Ala, L-His, L-Pro

L-Leu, L-Val, L-Ile

L-Ser, L-Thr

L-Glu, L-GIn

L-Asp, L-Asn

L-Met, L-Cys

L-Lys, L-Arg

L-Phe, L-Tyr, L-Trp 
Figure 4
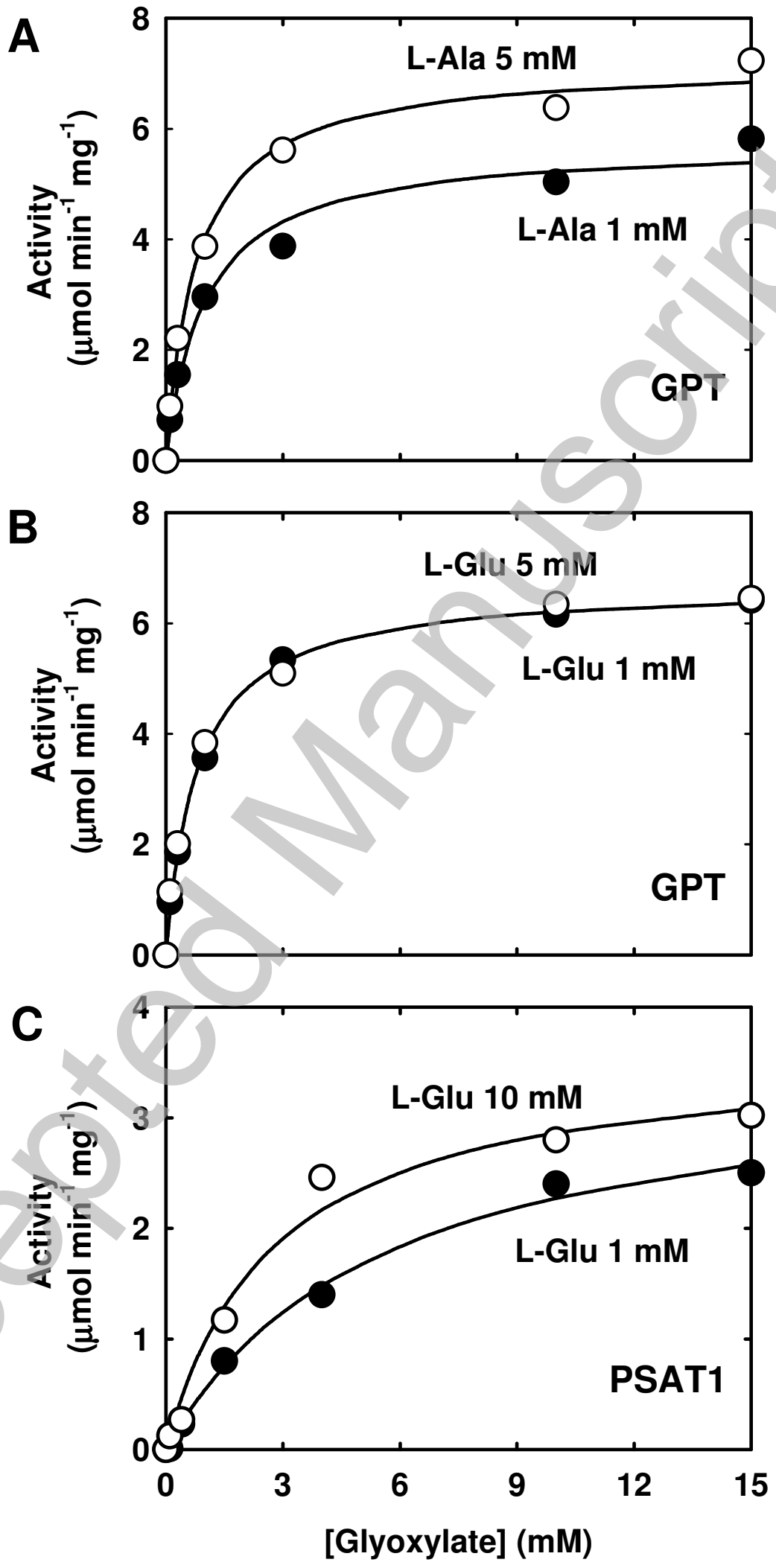


\section{Figure 5}

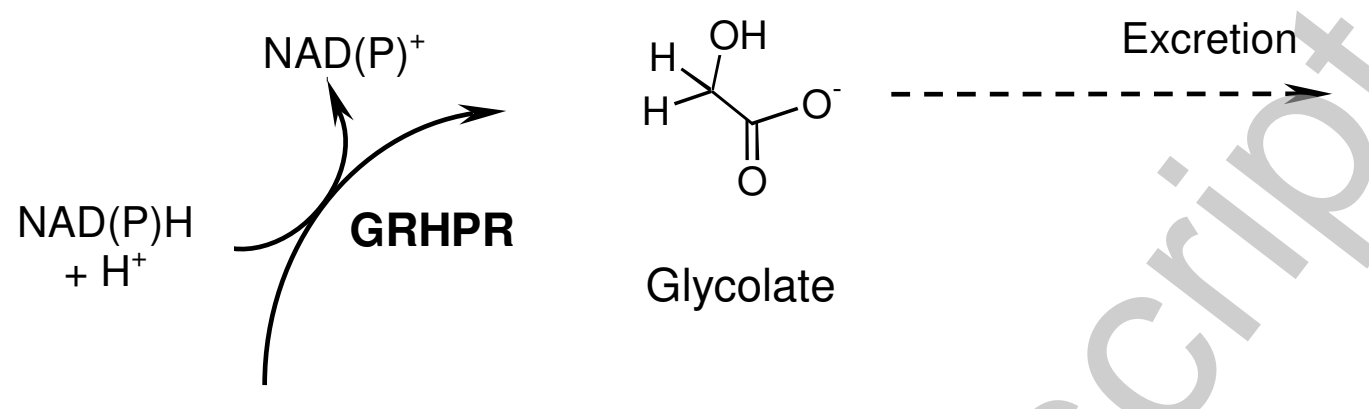

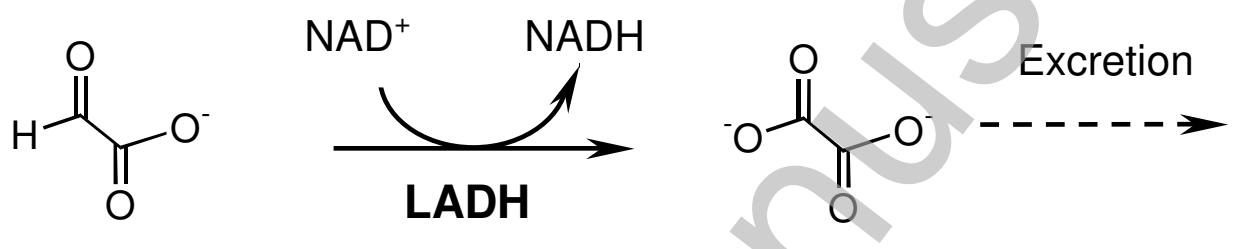<smiles>[Mg][Mg]O[GeH3]</smiles>
Oxalate

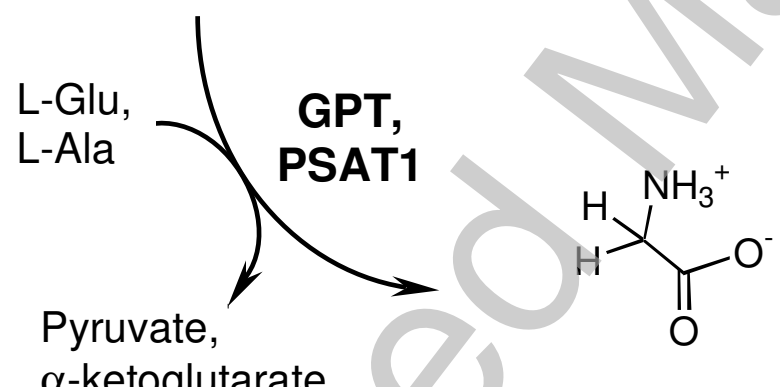

Glycine 